\title{
Optimisation of Photovoltaic System and Storage
}

\author{
John Boland ${ }^{1} \quad$ Fanny Boulaire ${ }^{2} \quad$ Adrian Grantham $^{3}$ \\ Chris White ${ }^{4}$
}

(Received 2 November 2016; revised 11 April 2017)

\begin{abstract}
Rooftop solar photovoltaic panels, household electrical energy storage (batteries), home energy management, interval metering and new tariffs will change the way that households use electricity from the grid. Distributed storage can give electricity retailers the ability to shift loads in response to changes in the wholesale price of electricity and constraints on the distribution network. What is the ideal mix of photovoltaic, storage and tariff for a customer? What is the value of these technologies to customers and to electricity retailers? In this paper we develop an algorithm that can help the customer size the photovoltaic panels and the battery to be installed, as well as choose which tariff structure would best suit them.
\end{abstract}

DOI:10.21914/anziamj.v58i0.11471, (C) Austral. Mathematical Soc. 2017. Published May 11, 2017, as part of the Proceedings of the 2016 Mathematics and Statistics in Industry Study Group. ISSN 1445-8810. (Print two pages per sheet of paper.) Copies of this article must not be made otherwise available on the internet; instead link directly to the DOI for this article. Record comments on this article via http://journal. austms . org. au/ojs/index.php/ANZIAMJ/comment/add/11471/0 


\section{Contents}

1 Introduction

M2

2 Literature review $\quad$ M5

2.1 Storage. . . . . . . . . . . . . . M5

2.2 Home Energy Management System . . . . . . . . . . M6

2.3 Customer behaviour . . . . . . . . . . . . . M6

2.4 Advanced analytics . . . . . . . . . . . . . . . . M7

3 Data management $\quad$ M8

3.1 Load data for Toowoomba and Townsville . . . . . . . M9

3.2 Load according to socio-demographic groups . . . . . . . M10

3.3 Load variation within a household . . . . . . . . . . . M13

3.4 Home Energy Management Systems . . . . . . . . . . . . M14

4 Simulation model $\quad$ M16

4.1 Modelling procedure . . . . . . . . . . . . . M17

4.2 Storage simulation - charging/discharging regimes . . . . M20

4.3 Example results . . . . . . . . . . . . . . . M21

5 Conclusion

M29

References

M30

\section{Introduction}

The electricity industry is changing, driven by multiple disruptive forces. This presents great transformation opportunities for both industry participants and consumers. We are shifting from a centralised energy model to a future energy model that is more dynamic and driven by: 
- Technology - with the increased uptake of photovoltaics (PV) for example, and the use of control software for home energy management;

- Electrical Energy Storage - with the availability of large and small-scale batteries;

- New electricity hungry devices - for example, electric cars;

- The Internet of Things - changing the way people interact with technology;

- Rapidly falling prices - of these new technologies;

- Policy - where tariffs and incentives are changing (including both energy and carbon);

- Competition - with new businesses and models, for example no upfront cost options;

- Customers - who are wanting choice, predictability, certainty and control, and want a simple, transparent and an effortless experience with their energy provider.

Customers are central to the transformation of the electricity sector, not only because they are the ones creating the demand, but also because of their changing role in respect to their electricity consumption. With the introduction of rooftop solar panels, some individuals have moved from being consumers only, to being prosumers. Being a prosumer means one is not only consuming electricity from the grid but also producing electricity and sending it to the grid. This shift has given them the opportunity to be more active in the management of their electricity, as they are more aware of their own usage and production, as well as how they can better manage them, facilitated by home energy management systems (HEMS). We further expect that with the falling prices of batteries, household storage systems will become widespread, reinforcing the trend of more people becoming actively involved in management of their electricity usage. 
While at this stage, only early adopters or people under trials from electricity providers use these technologies, it is expected that they will become mainstream before long. Knowing the ideal mix of PV, storage and tariff for a customer is therefore important, if such systems are to be taken up. For greater uptake of these technologies, there needs to be value for both the customers and the electricity retailers.

A pilot project ${ }^{1}$ is being run over three locations (Cannonvale, Toowoomba and Townsville), with a virtual power plant system to explore the multiple value streams. By virtual power plant we mean a system combining a number of sources of energy like wind and solar plus battery storage to provide a reliable supply. Figure 1 shows a representative illustration. The Australian Renewable Energy Agency (ARENA) provided $\$ 400,000$ towards this pilot. The customer value proposition is that it provides

- Savings for the customer,

- Future price protection,

- Renewable energy, and

- Back-up power.

In order to achieve all these benefits, the mix of PV, storage and tariff needs to be right for both the customer and the energy retailer. The MISG project investigated the different options. This paper presents the various aspects undertaken by the team towards solving the problem of how to estimate the value to the customer of various combinations of PV, storage and tariffs. A literature review was undertaken (Section 2), data was collected and analysed (Section 3), and a simulation-based solution adopted (Section 4).

\footnotetext{
${ }^{1}$ https ://www.ergon.com.au/retail/residential/hybridenergy
} 
Figure 1: Trial configuration. [Ergon Energy Retail, https://www.ergon. com.au/retail/residential/hybridenergy]

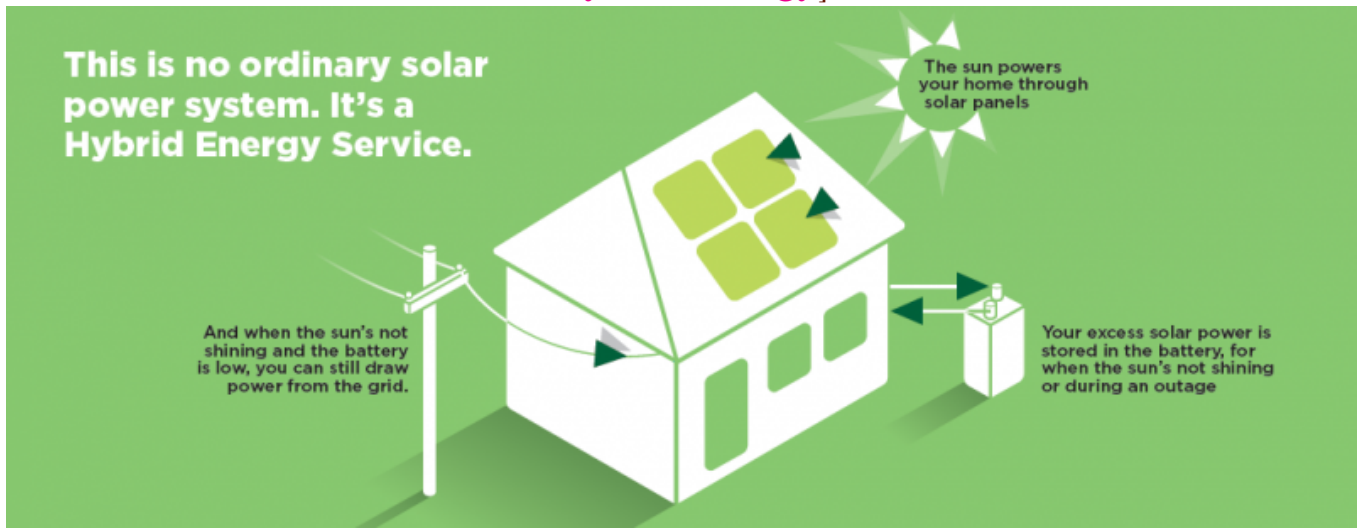

\section{Literature review}

\section{$2.1 \quad$ Storage}

In recent years, the cost of batteries has decreased greatly, decreasing $14 \%$ annually from 2007 to 2014 [8], and is expected to decrease further. Thanks to the interest from the automotive industry for their electrical vehicles, battery costs have been more than halved in seven years due to more efficient battery productions and higher production volumes. Further decrease in costs is expected in the next few years as inverters, which are the most expensive part of the battery, are predicted to see the greatest decline in cost [2]. These decreases in the costs of battery packs to power electric vehicles (EV) are then expected to benefit the residential sector where they could have a second life by being repurposed as household batteries [12]. This will make it very affordable in the near future for individual customers to have their own storage. Then solar PV, along with EV and batteries are expected to make rooftop solar viable without subsidies, even giving the customer twelve years of 'free electricity' [9]. 
While storage at present remains relatively expensive, it is still possible to achieve some return on investment by monetising the various value streams that storage creates: including

- potentially utilising the relatively low cost of solar and off-peak periods of Time of Use (TOU) tariffs against periods when tariffs are high; and

- managing storage at scale as a 'Virtual Power Plant', to import and export power at specific times to provide services to electricity networks and retailers.

\subsection{Home Energy Management System}

Home energy management systems (HEMS) are central to managing how the electricity is consumed and when. When a house is fitted with PV and storage, HEMS decides when the excess energy from PV will be stored, by trying to optimise the state of charge (SOC) of the battery, or when needed, when it is going to be fed back into the grid $[1,3,13]$ depending on price. Other criteria for optimising the SOC of the battery such as using the storage for ancillary services [1] or minimizing electricity costs, voltage deviation, feeder losses and renewable energy curtailment from the point of view of the distribution network [13] are also decided upon. This paper focusses on the value of PV, storage and HEMS from the point of view of the customer, and the retailer.

\subsection{Customer behaviour}

In order to optimise the state of charge of the battery, the household consumption needs to be well estimated as the HEMS algorithms are based on predictions for it as well as the expected PV output [3]. The algorithms for the HEMS control then need to be adapted to the individual needs of the household. They need to be reformulated for each of the different types of customers and cannot simply be the same for everyone. Indeed, the number 
of factors influencing the electricity consumption is large, as described by Jones et al. [4] where 62 factors that potentially influence domestic electricity consumption were identified as part of a large literature review. Amongst these identified factors, 13 were socio-economic, 12 related to the dwelling characteristics and 37 to the types of appliances. Developing scheduling algorithms taking these factors into account is therefore important. Jovanovic et al. [5] proposed an energy scheduling framework that considers different types of households classified by family composition, status and number of occupants. The customer preferences when scheduling the HEMS activities were also considered, making the constraints of the PV and storage system more acceptable from the point of view of the customer. While flexibility was offered by allowing the scheduling of the use of the appliances within a time window, a reduction in electricity consumption costs could still be obtained.

\subsection{Advanced analytics}

Until the industry moves towards full monitoring of household consumption and the development of learning algorithms, it is difficult to provide a fullypersonalised offer for an optimised sizing of PV and battery and its scheduling. In the meantime, it is possible to identify classes of customers, for which a cost benefit of the use of batteries and PV can be performed. Clustering techniques can be used to group customers according to their electricity consumption [7], some of which can be general purpose, or specifically designed for the specific purpose of demand-response [6], which would be most appropriate for the types of applications considered in this paper. From the identification of groups of customers with similar electricity consumption patterns, the retailer can design and offer different packages, as well as adapt the prices to benefit both their business and the customer.

In conclusion, to fully utilise investment in storage it needs to be managed as part of an ecosystem, including 
- Storage,

- Home energy management technology,

- Customer behaviour, and

- Advanced analytics.

Understanding how this ecosystem works and how the benefits of storage can be accessed by customers, retailers and networks is a key objective of Ergon Energy Queensland's current residential storage pilot. Within this context, this MISG project focussed on estimating the value to the customer of various combinations of PV, storage and tariffs.

\section{Data management}

Because of the choice of a simulation-based approach, understanding the available data (publicly available, generic and modified) was essential. Different types of data were available from different sources and for different time-scales

- Load - the incremental electricity demand for the household

- National Electricity Market (NEM) half-hourly load profiles data for Queensland, for a full year,

- Half-hourly load profiles for generic households in Toowoomba and Townsville, Queensland, for a full year,

- Half-hourly load profiles over two months for a collection of 33 households in Toowoomba and Townsville.

- PV Supply

- Half-hourly PV output for generic profiles in Toowoomba and Townsville, for three orientations (north, west and east). The profiles were selected by Ergon to be representative of the demand 
behaviour for households in Toowoomba (peak winter heating demand) and Townsville (peak summer cooling demand),

- Average day for each month from July 2015 to January 2016 (seven months), at 15 minutes interval, for 53 households in Townsville.

- Batteries

- Battery soc for 33 households for two months, in Cannonvale, Toowoomba and Townsville.

- Tariffs

- Tariff 11 and 12 (specifically 12A) as described in the Queensland Government Gazette for residential customers [11]. Tariff 11 is such that the price per unit of electricity is the same regardless of the time of the day; and Tariff 12A has a peak price applied between $3 \mathrm{pm}$ and $9.30 \mathrm{pm}$ during the summer months (December to February inclusive). These conditions apply to import from the grid. For export, we assumed the same price as Tariff 11 in all instances.

- Home Energy Management Systems

- Average day for each month from July 2015 to January 2016, at 15 minutes interval, for different loads such as air-conditioning and pool pumps. This was determined by a simple averaging process for each 15 minute interval.

From the different datasets available, we explored the data to understand those different sets and create new ones to act as input to the simulation.

\subsection{Load data for Toowoomba and Townsville}

Load profiles were plotted to understand how load varies for two locations in Queensland and for different data types. Figure 2 shows the location of 
the two example towns. These two locations are of interest because of the patterns of consumption over a year, where Townsville peak consumption occurs during the summer months (Figure 3), due to air-conditioning, and Toowoomba peak consumption occurs during the winter months (Figure 4), due to heating.

We have examples of electricity consumption and PV output for three identical days from the different load datasets. These show how different sources and format give more or less accurate and reliable output if used in the simulation. It is then very important to carefully choose the dataset when considering the problem. Further, it is difficult to give a general answer because, depending on the location and the household lifestyle, the situation will be different. Figure 5 gives the average residential plus commercial load in Queensland. Figure 6 gives a baseline idea of the load and supply for residences in Toowoomba, and data for a specific household is shown in Figure 7. However, these different datasets are used to answer different sub-questions from the initial one. As such, the load profile from the NEM (the first set) would be used to answer a question about how much revenue might be lost by the retailer from clients using batteries en masse; while the latter two can be used to understand how batteries and home energy management systems help individual customers save on their electricity bills.

\subsection{Load according to socio-demographic groups}

A subquestion arose regarding the possibility of grouping customers according to their consumption so that Ergon Energy Retail (EEQ) can identify clusters of people to offer a package of PV and battery configuration suited to their particular consumption profile. Work on clustering of electricity consumers has already been done in a previous MISG [7], so the clustering of consumers was not thoroughly investigated, but understanding how electricity use might vary was investigated.

The data provided contained information about which socio-demographic 
Figure 2: Sample Locations

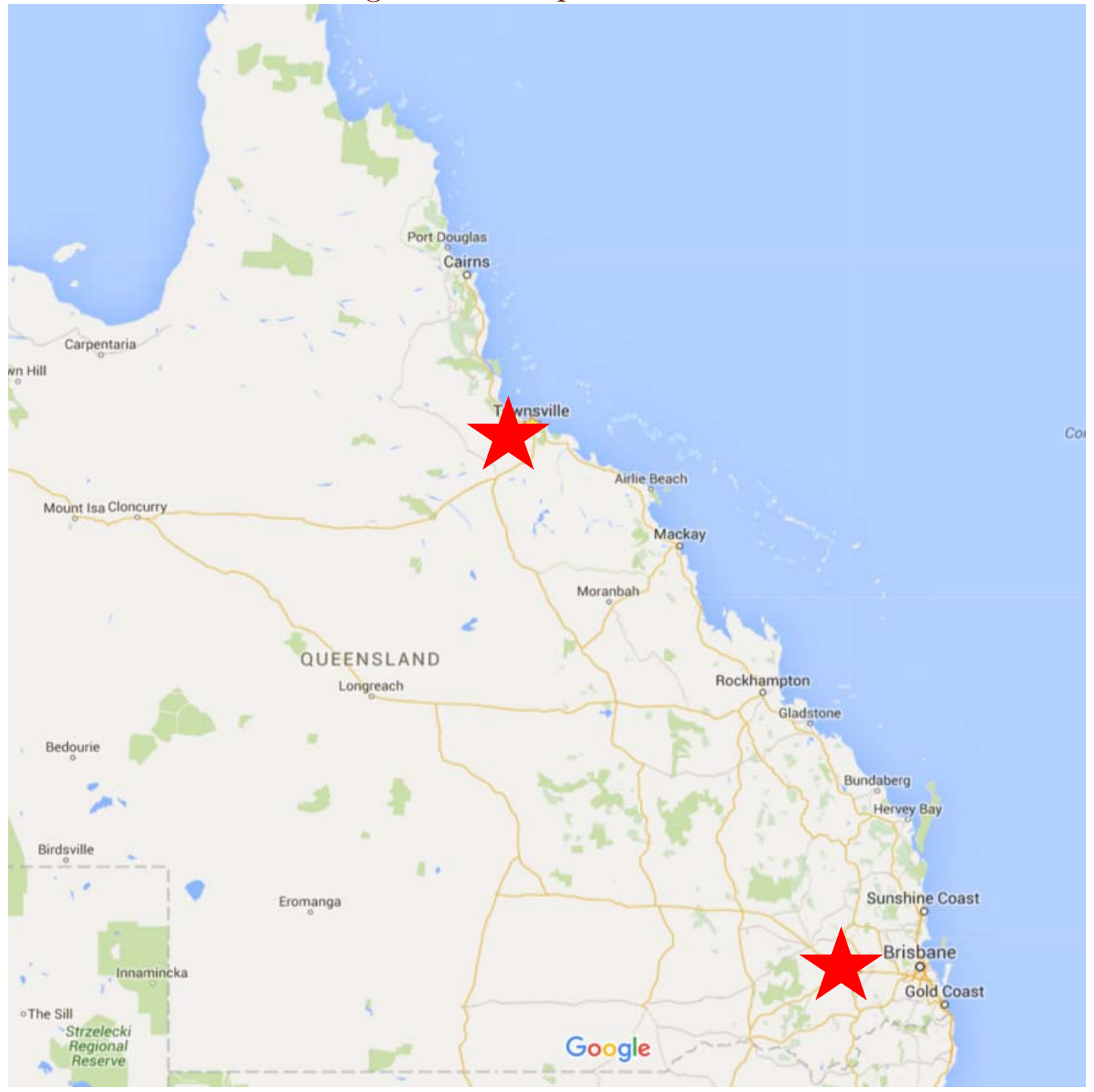


Figure 3: Load with summer peak

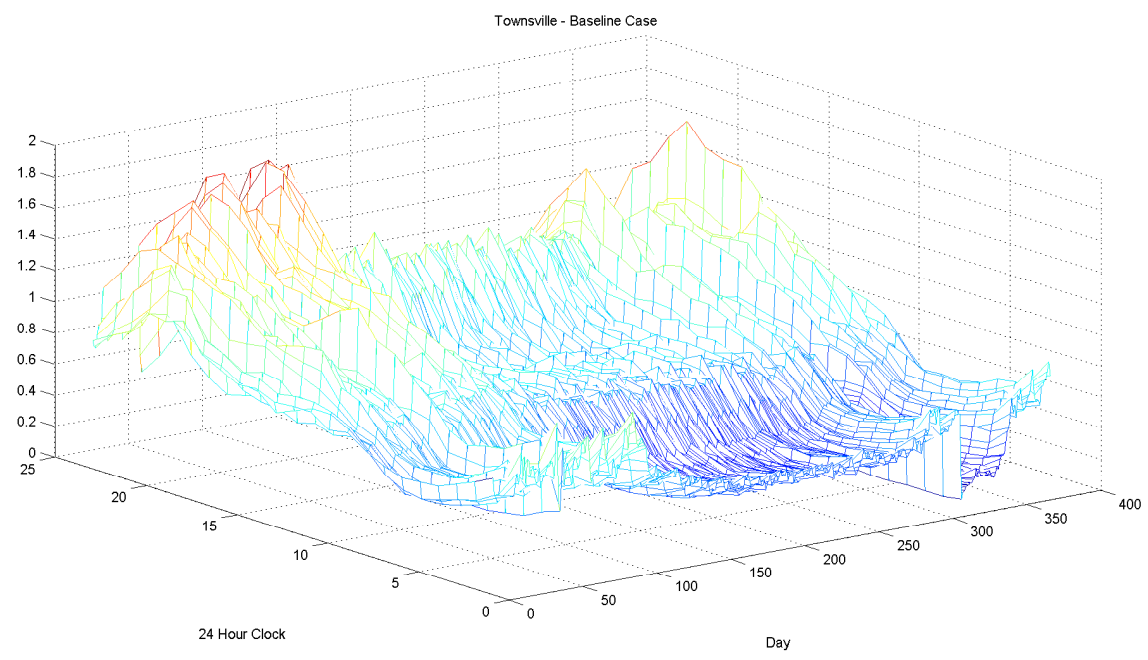

Figure 4: Load with winter peak

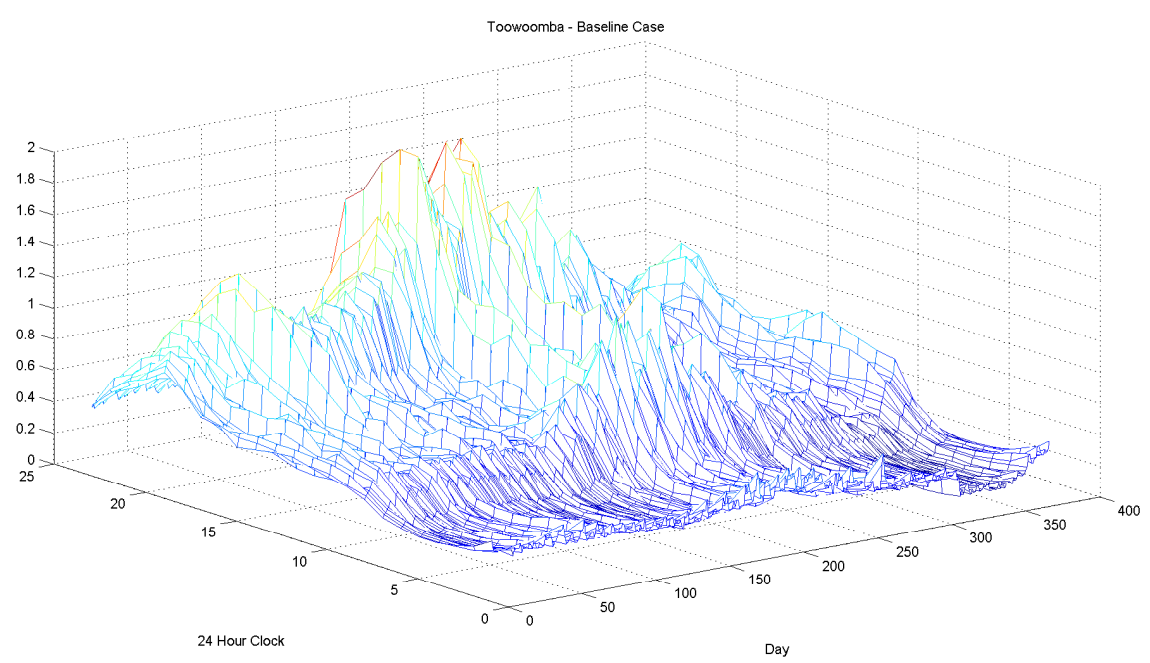


Figure 5: Residential plus commercial load for Queensland

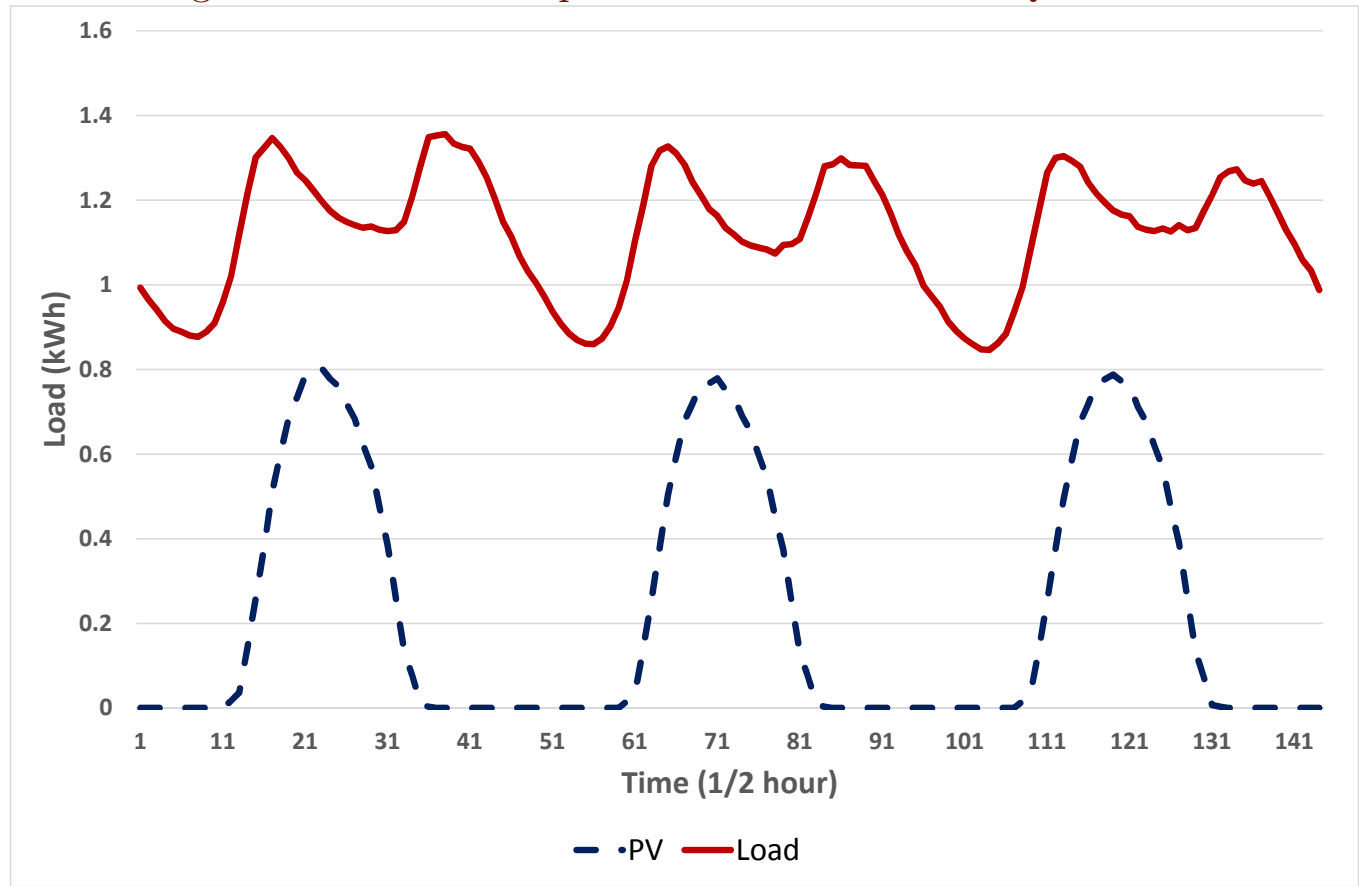

group a household belongs to, enabling analysis of the different patterns of consumption these might have. Four groups were given: empty nesters, mature families, singles and young families. Figures 8 and 9 show the daily average and standard deviation for these four groups, indicating some variability between the groups but also within.

\subsection{Load variation within a household}

Looking at the data for a single dwelling, Figures 10 and 11 show great variation in the household consumption. Figure 10 shows the demand for a household on the 1st of January 2016 as well as on the 14th, where there is a 
Figure 6: Baseline data for Toowoomba households

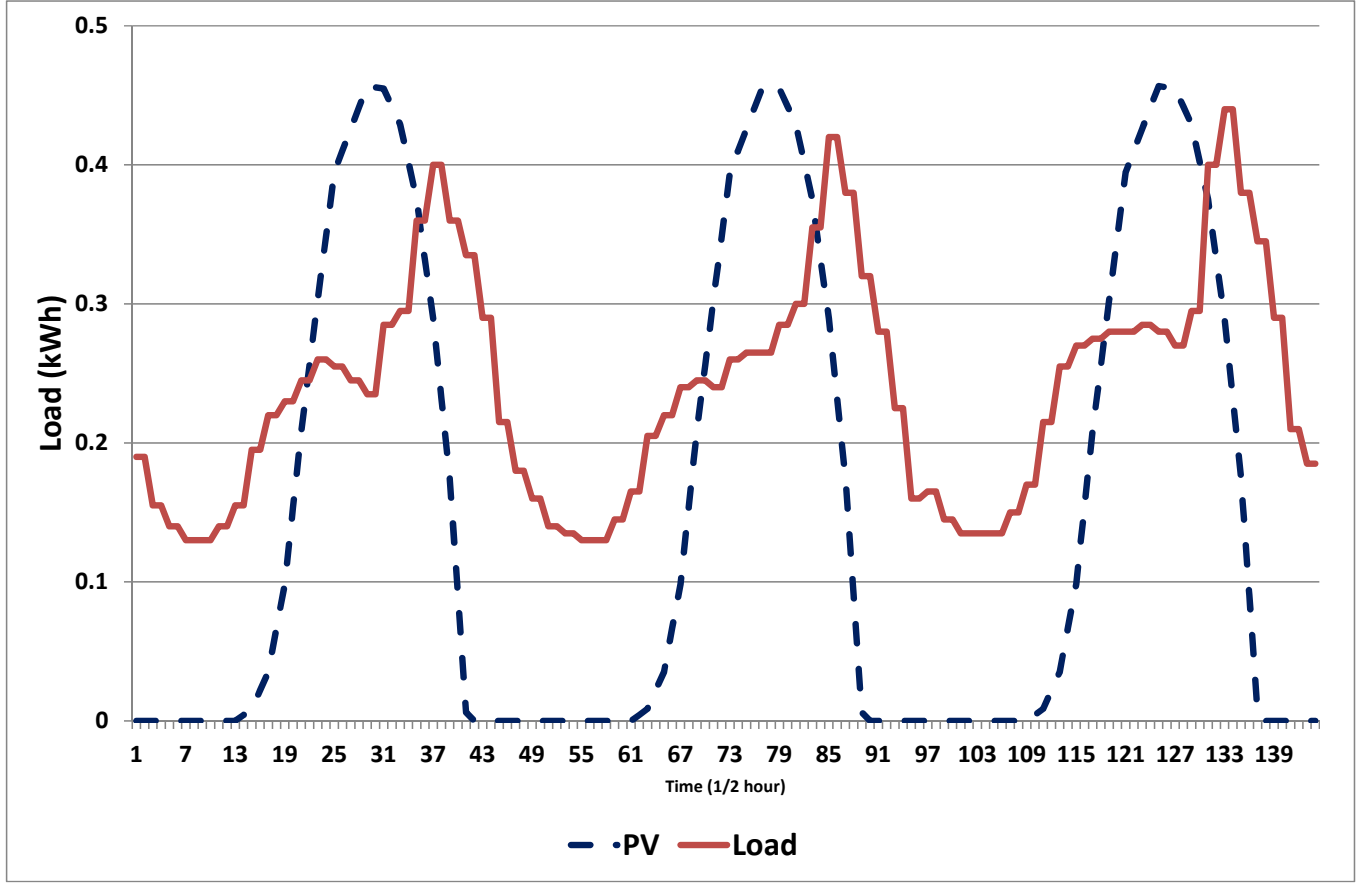

great variation in terms of time of use during the day as well as amplitude in the demand. Figure 11 captures this variability for the month of January only, where the average and the standard deviation for that same dwelling are shown. We expect that this variability would even be greater when considering the whole year, because of seasonal variation.

\subsection{Home Energy Management Systems}

Another investigation within the data was regarding the use of home energy management systems and how they can be used within the home and the impact they might have on the consumer's savings. 
Figure 7: Load and supply for one specific home in Toowoomba

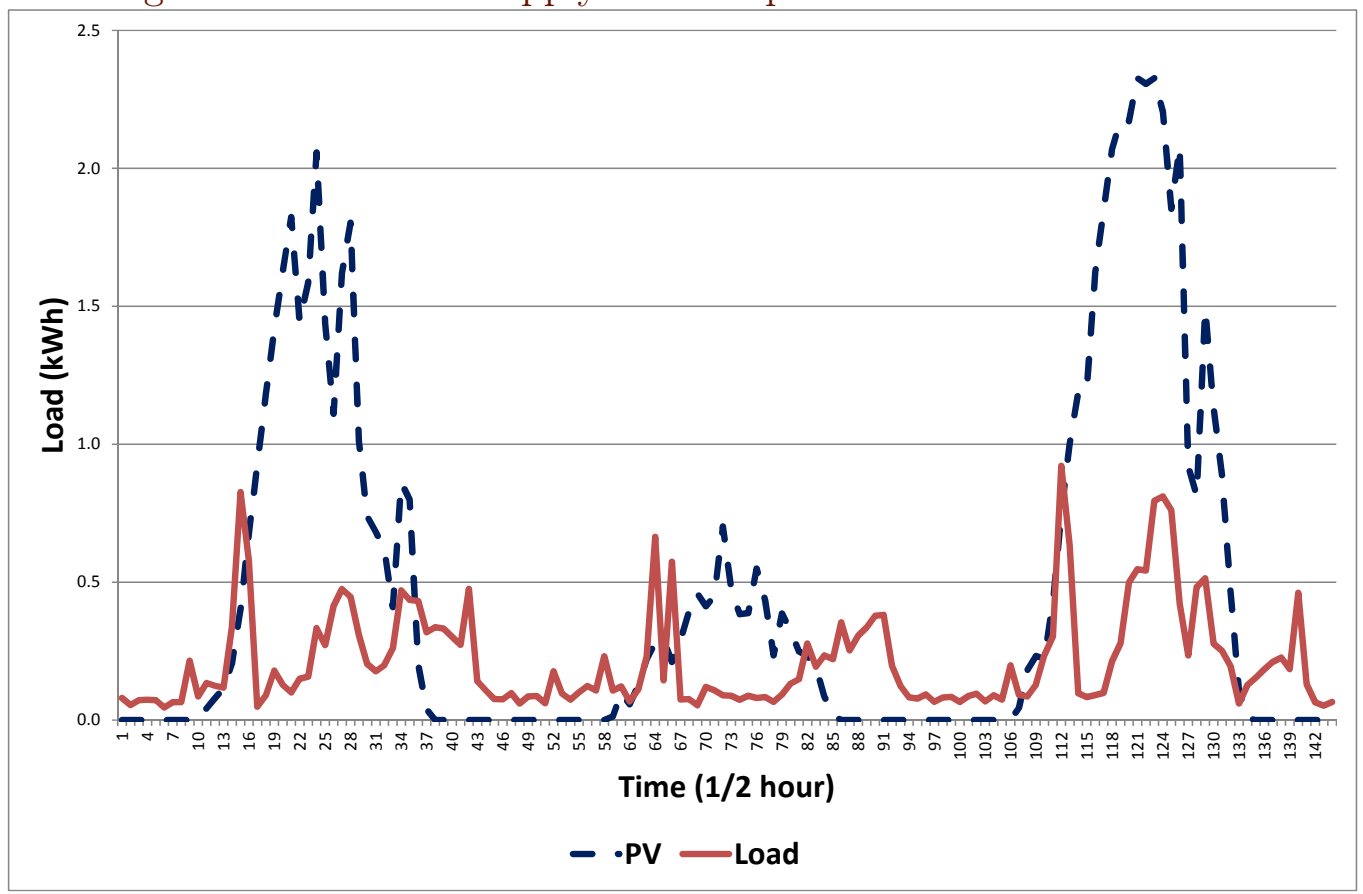

Figure 12 shows an example of the type of data available, where the average daily consumption for seven months is plotted for a household with a PV output and pool pump load. In this diagram, most of the demand from the pool pump is covered by the output from the PV showing that the size of the PV is sufficient to cover this load, and the time of use for the pool pump appropriate as it coincides with the time of PV output.

HEMS are used to best manage the house loads, and are important when batteries are installed. However, with the right sizing of PV and controls of appliances, a HEMS might also be an alternative to a battery. 
Figure 8: Average daily load for different socio-demographic groups in Toowoomba

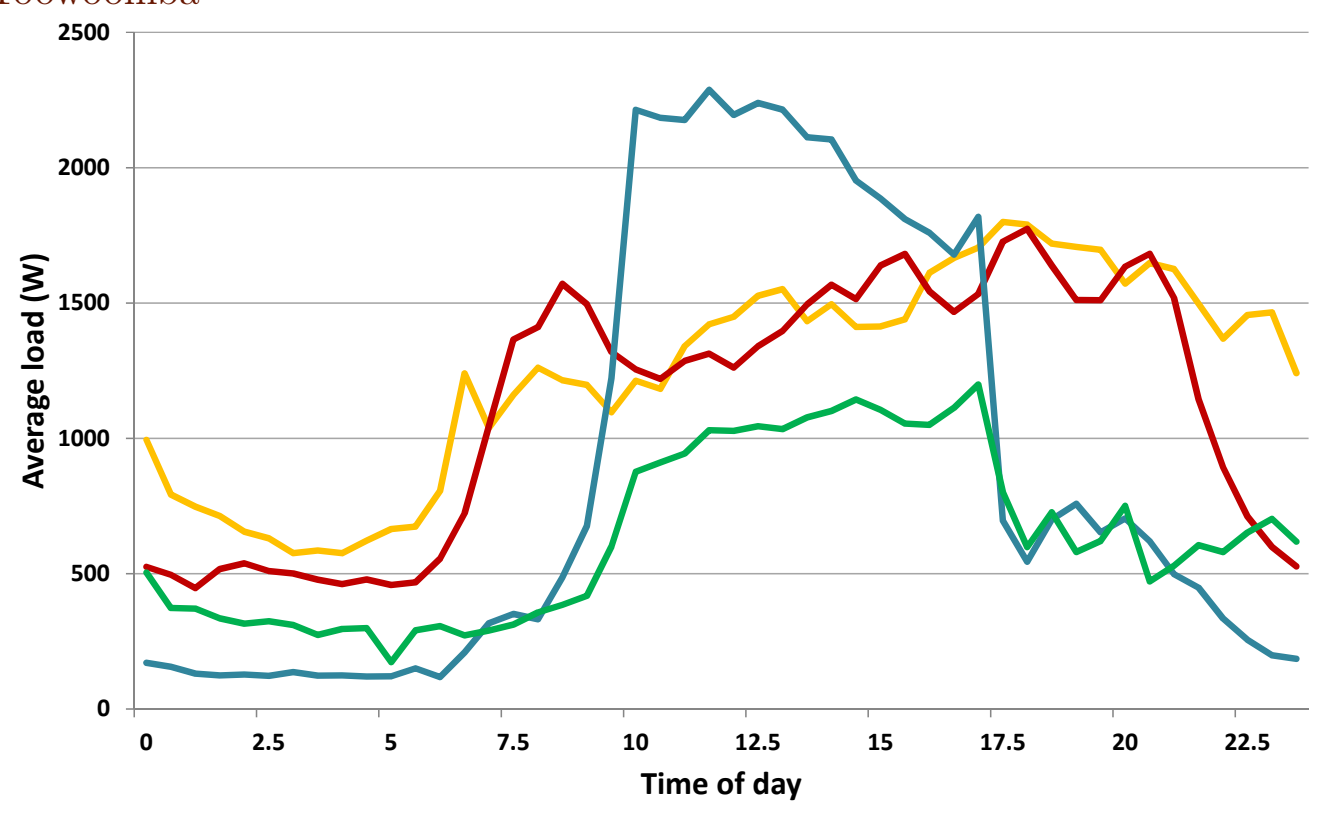

- Average of Load - Mature Family - Singles - Young Family

\section{Simulation model}

An existing simulation model, implemented in MATLAB for different mixtures of PV and storage for households Lochiel Park, formed the basis for the simulations carried out in this MISG project. The initial simulation model was developed as part of a project for the Cooperative Research Centre for Low Carbon Living [10]. Changes to the initial code to suit the goal of this project included:

- Timescale - from one minute to half an hour,

- Changes in battery protocols, 
Figure 9: Standard deviations for different socio-demographic groups in Toowoomba

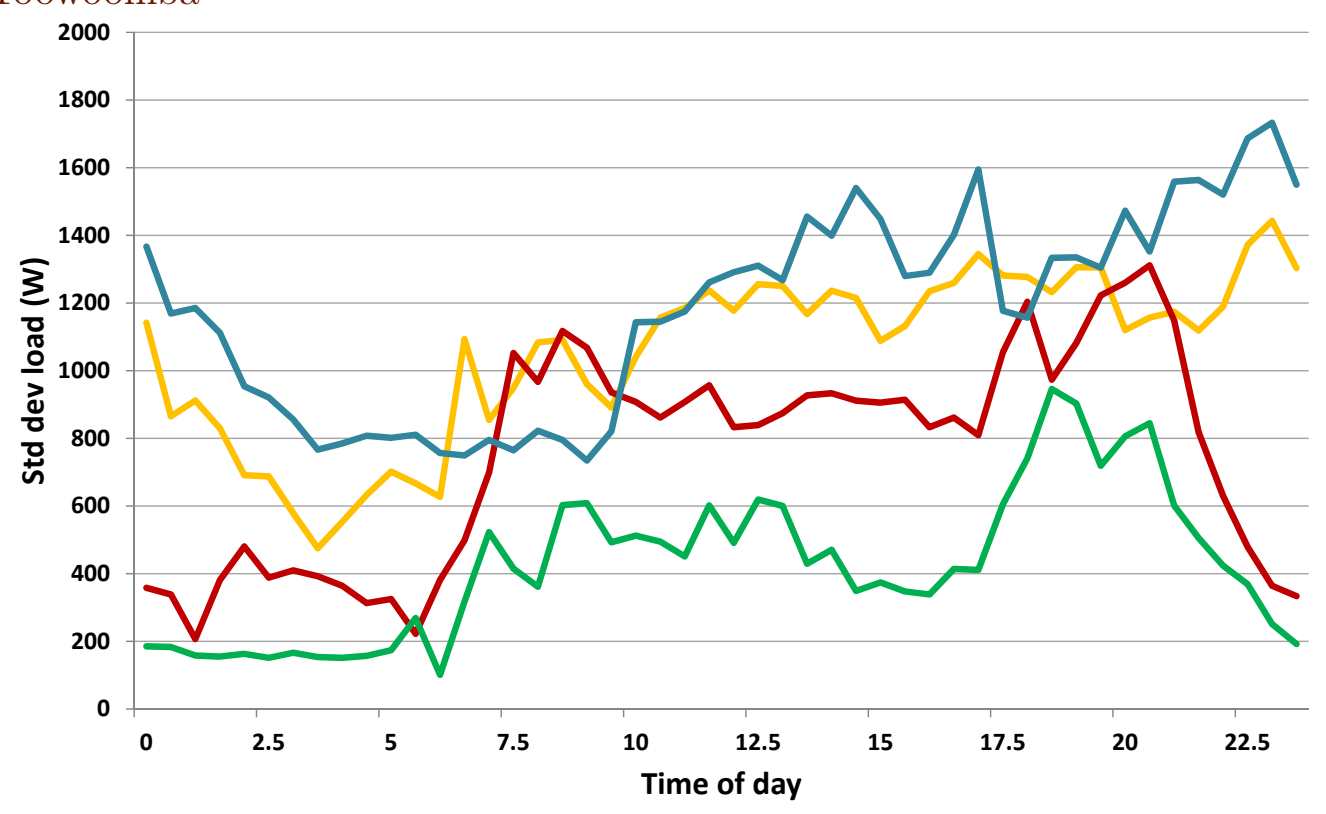

—Average of Load —Mature Family —Singles —Young Family

- Tariffs - addition of multiple possible tariffs.

The approach used here was to start with the model for simple situations and then add complexity.

\subsection{Modelling procedure}

The goal of the simulation model is to estimate the savings on the electricity bill with different combinations of PV and storage.

This was done under two tariff structures: 
Figure 10: Load of one dwelling in Townsville on (a) 1st and (b) 14th of January 2016.

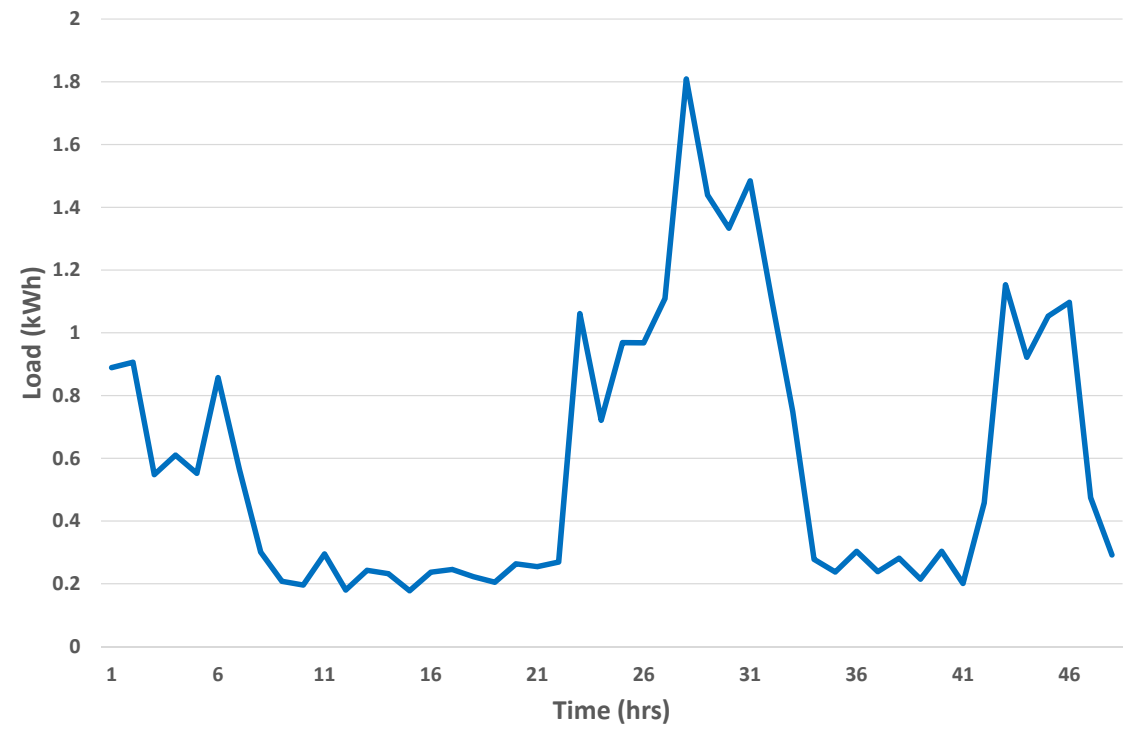

(a)

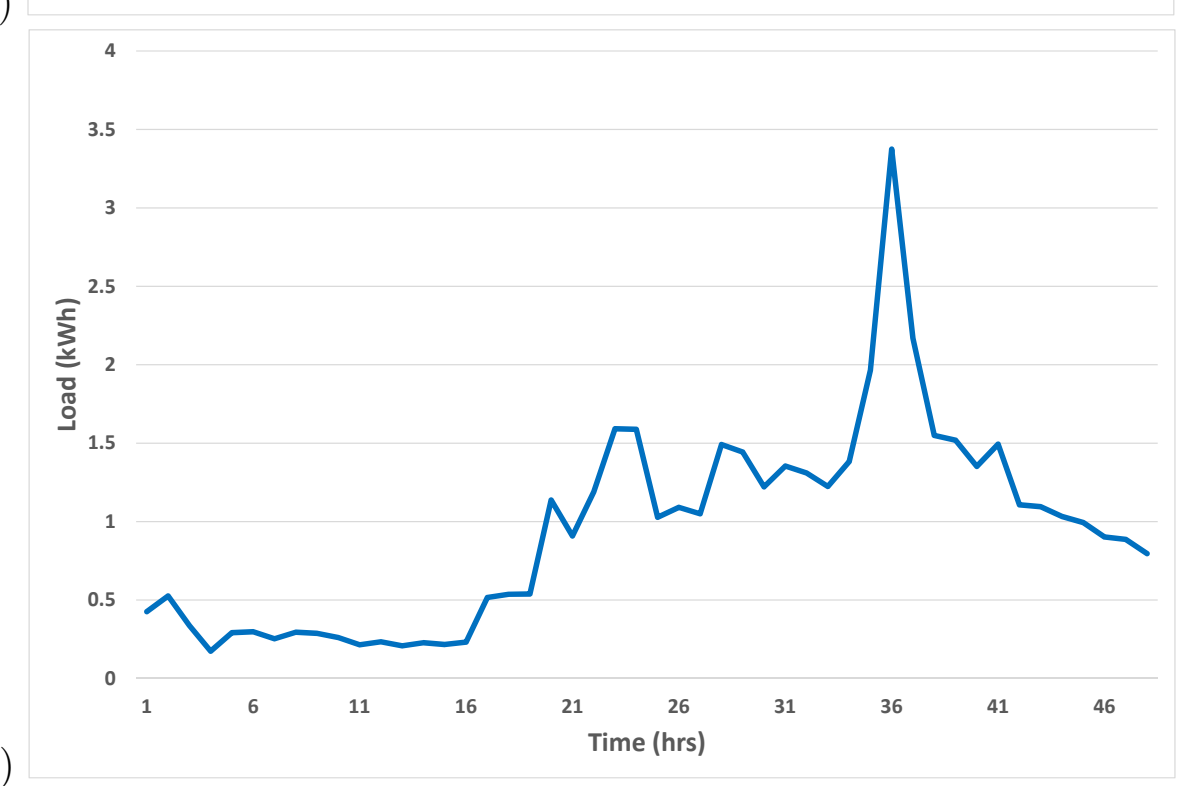


Figure 11: Average load over the day with one standard deviation (bar) for all days in January 2016 for the same dwelling in Townsville.

1.4

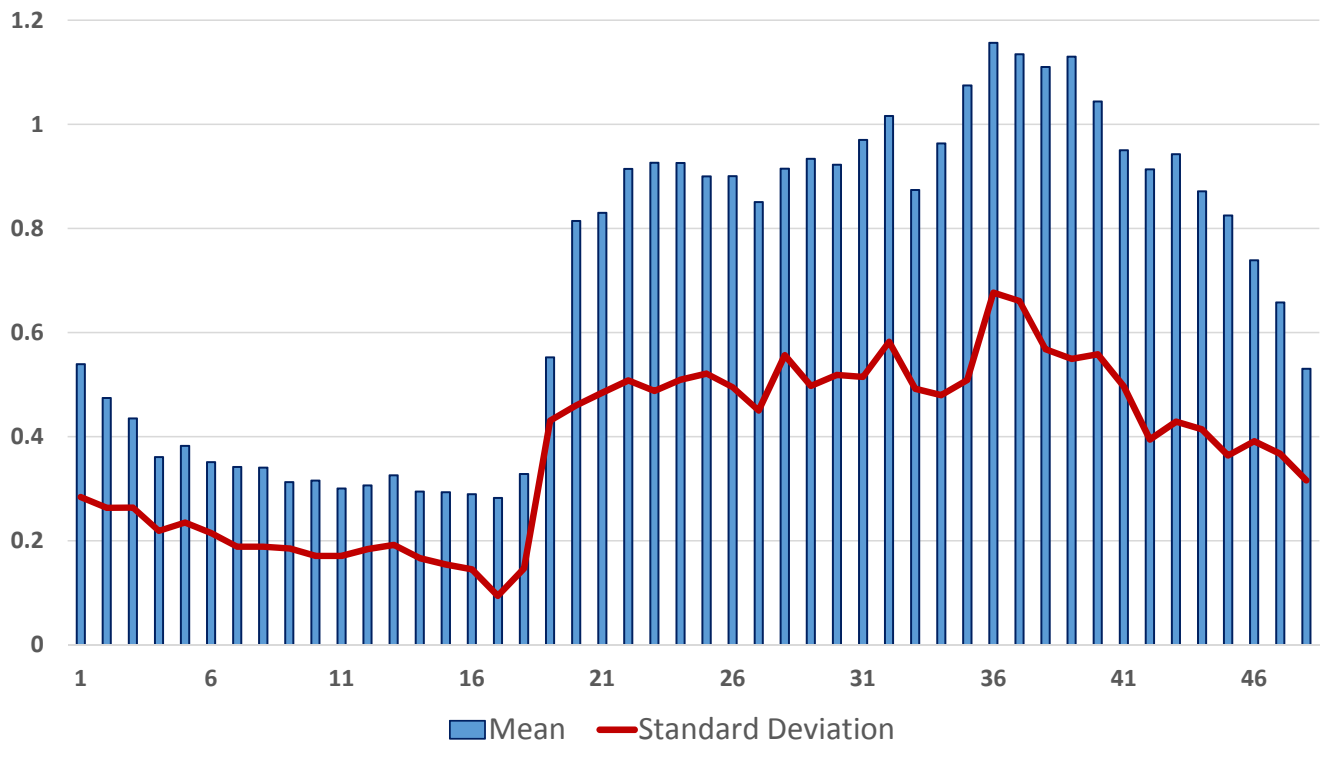

Figure 12: Daily average pool pump usage and PV output

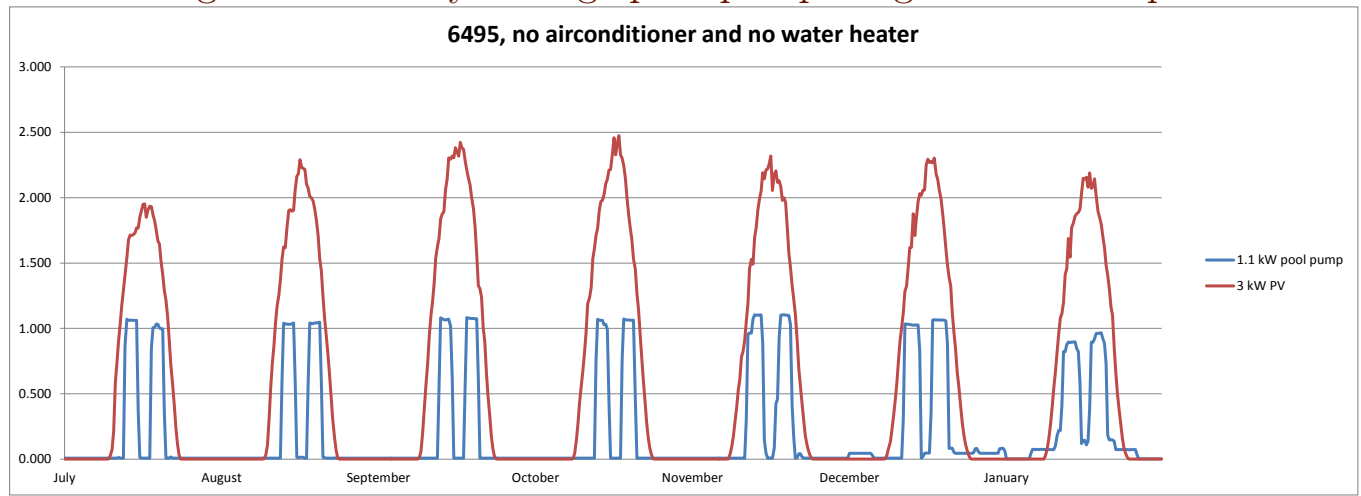


- Flat rate (Tariff 11), and

- Time of use (Tariff 12A) - made of three periods: shoulder and peak (3-9:30pm) during the summer months, and off-peak outside those hours.

The simulations were performed with the data constructed with half-hour load and PV output profiles for one year. This could be extended to use several years of synthetic data. While the operation of the battery system was simulated (see below), the PV output was scaled from recorded data. This means that if the PV output in the data was for a $2 \mathrm{~kW}$ system, it was scaled up and down to cover the range of installations from 1 to $10 \mathrm{~kW}$ (for example, multiplied by five for a $10 \mathrm{~kW}$ system).

The savings, obtained from the simulation, can then be used in conjunction with the costs involved in setup and maintenance of the systems to select the most appropriate option.

\subsection{Storage simulation — charging/discharging regimes}

The procedure for each tariff type is as follows.

- With a flat tariff:

- At each half hour, check the load consumed in the previous half hour along with the electricity generated from the solar PV,

- If solar > load, then meet the load requirement, charge the batteries, and only when the storage is full, export the excess to the grid (and receive payment for this),

- If solar < load, then meet the load requirement (which may require taking some from storage), and if that is not enough, import from the grid (and pay for this).

- With a time of use tariff: 
- Except for the peak/shoulder time intervals, use the procedure above,

- In the peak/shoulder period, use solar and discharge to meet load, before any imports.

- In addition, with a storage policy targeting a full store at the start of the peak/shoulder period

* complement charging the battery from excess PV with electricity from the grid, if necessary. Achieving this goal requires estimating the right time at which to start importing from the grid, which is constrained by the charging rate of the battery, as well as an accurate estimation of the expected dwelling load and PV output.

* with a time of use tariff, the aim is to minimise import during the shoulder/peak period (when price is the highest) by using the battery charged from excess PV generation

\subsection{Example results}

Simulations were run with one load profile extracted from the original Lochiel Park dataset. This choice of data, as opposed to the datasets mentioned in the previous section, was due to time constraint and division of the work amongst small groups, as clean data was required immediately by the simulation team. Because data analysis had already been performed on the Lochiel Park dataset, it was deemed reliable and useable at the start of the project week. We expect that the other datasets would provide similar results to the ones presented below.

Figure 13 gives the chosen household consumption. It has a typical residential shape where two peaks are observed (one in the morning and one in the evening). However, the first peak is quite late compared to the national 
Figure 13: Household Consumption: (a) Daily Average; and (b) Boxplot Average Daily Consumption

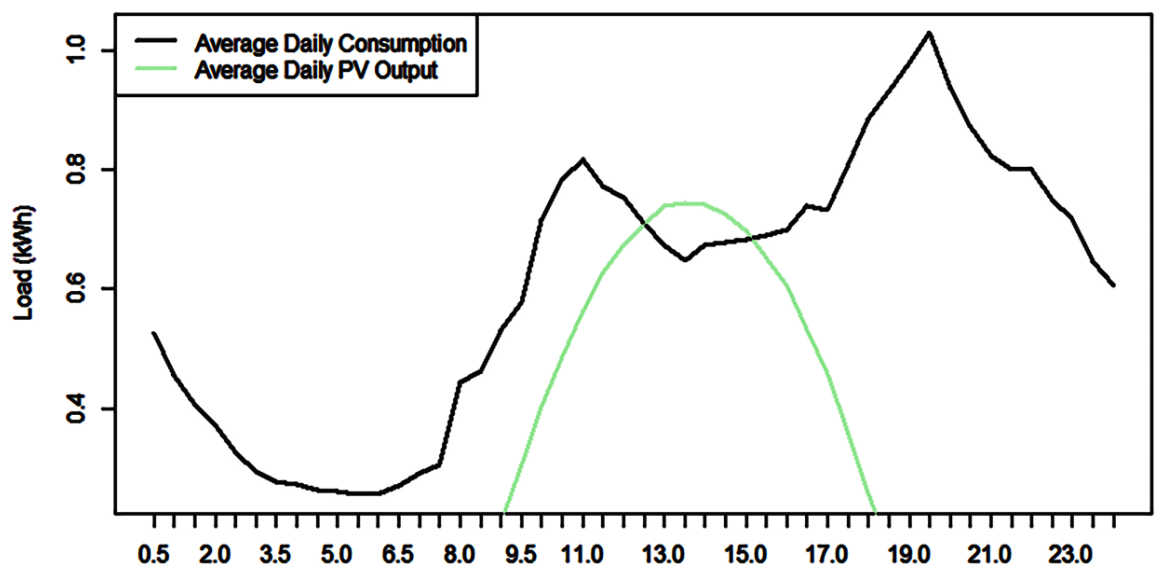

(a)

Time of the Day (1/2 hour)

\section{Boxplot of electricity consumption}

(b)

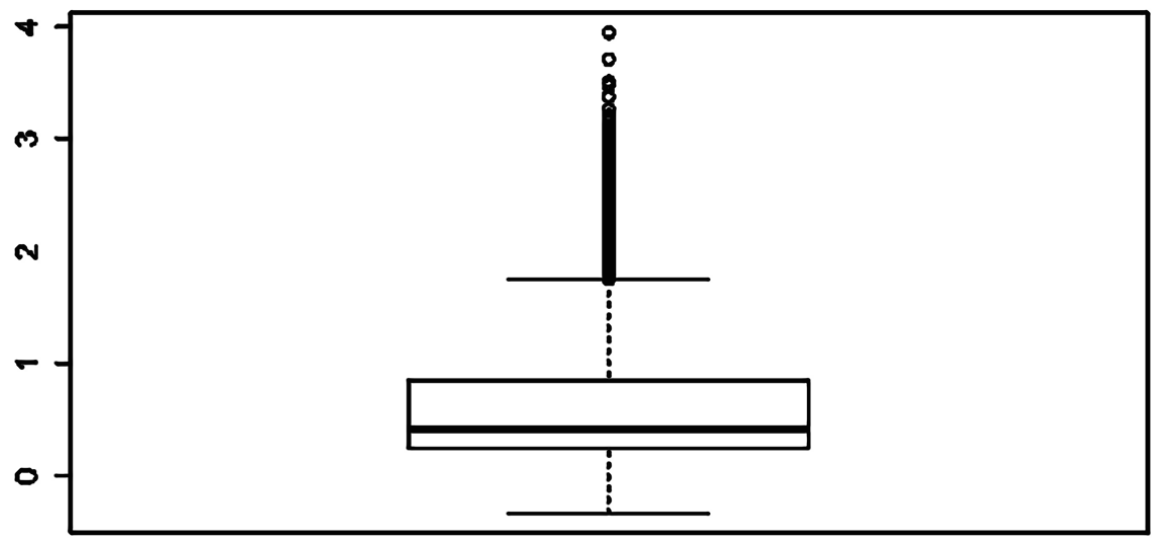


average, which means that more PV output can then be used by the residence in the morning. The boxplot graph shows the spread of the load consumed: most of the load is less than $1 \mathrm{kWh}$ per half hour, with some peaks up to $4 \mathrm{kWh}$ per half hour.

Four simulations were performed using two tariff types (11 and 12A) as described a Queensland report [11]. Tariff 11 is such that the price per unit of electricity is the same regardless of the time of the day; and tariff $12 \mathrm{~A}$ has a peak price applied between $3 \mathrm{pm}$ and $9.30 \mathrm{pm}$ during the summer months (December to February inclusive). Different policies were applied in the simulations.

- Simulation 1-Use of tariff 11 with storage policy such that the load is satisfied first, and then any excess is stored. This means that whenever there is surplus production from the PV (i.e., not used by the dwelling), this excess is stored in the battery.

- Simulation 2-Use of tariff 12A with storage policy following load and charging battery from excess PV output.

- Simulation 3-Use of tariff 12A with storage policy targeting a full store at the start of the peak/shoulder period. This means that the excess electricity from PV is used to charge the battery during the off-peak period, complementing it with electricity from the grid if PV production is not sufficient, so that when the peak or shoulder period happens, it is then ready to discharge. This could be achieved with the use of HEMS.

- Simulation 4-Use of tariff 12A with storage policy targeting a daily store level based on precisely knowing PV and load data. This means perfect knowledge about electricity consumption and PV production. This is the best-case scenario that can be achieved.

Tables 1, 2, 3 and 4 show the result of each simulation. Each entry indicates the potential cost savings to the customer (shown by a negative sign) for a particular size of batteries and PV (ranging from 1 to $10 \mathrm{~kW}$ for PV, and 1 to $10 \mathrm{kWh}$ for battery). In each case, the reported saving is relative to the 
situation in which there is no PV and no battery.

Simulations 1 and 2 both show that without PV, there is no saving because of the battery protocol used. In both cases, the aim is to avoid drawing from the grid by using the generation from PV directly to cover the load, or if still in excess storing it in the battery. The battery in this case does not charge from the grid at all.

Using such a policy for tariff 11 makes sense because whatever electricity is used to charge the battery will be coming from the grid at the same price as if this electricity had been used directly to cover the load of the dwelling. Using a battery without a PV installed or a time of use tariff would be more costly than using the electricity directly from the grid, because of the losses incurred when charging and discharging the battery. Simulation 2 had the same policy to see the direct impact on cost as a result of tariff change.

When comparing the billing costs for these two simulations, tariff 11 was more costly than tariff $12 \mathrm{~A}$ (by about $\mathrm{A} \$ 400$ ), regardless of the size of the PV and the battery. This means that in that particular case, the consumer would save money by simply switching from tariff 11 to tariff $12 \mathrm{~A}$, even without changing their consumption behaviour. This is due to the particular way this dwelling consumes, where a lot of the load can be covered by the PV during the day and when it is not (the evening) the load is not great (about $1 \mathrm{kWh}$ over half an hour).

Using simulations 1 and 2, consumers who have already installed a PV system and/or a battery can then compare the savings they would make depending on the tariff they use.

In simulation 3 and 4 , the grid is used to charge the battery during off-peak if the PV is not sufficient to ensure the battery is full by the time of the shoulder/peak period. This is so that the battery can be used to cover the premise load when the price is the highest. With simulation 2, the battery might not have been full at that time, and therefore less might then be used from the battery to cover the load during peak period, resulting in potential 


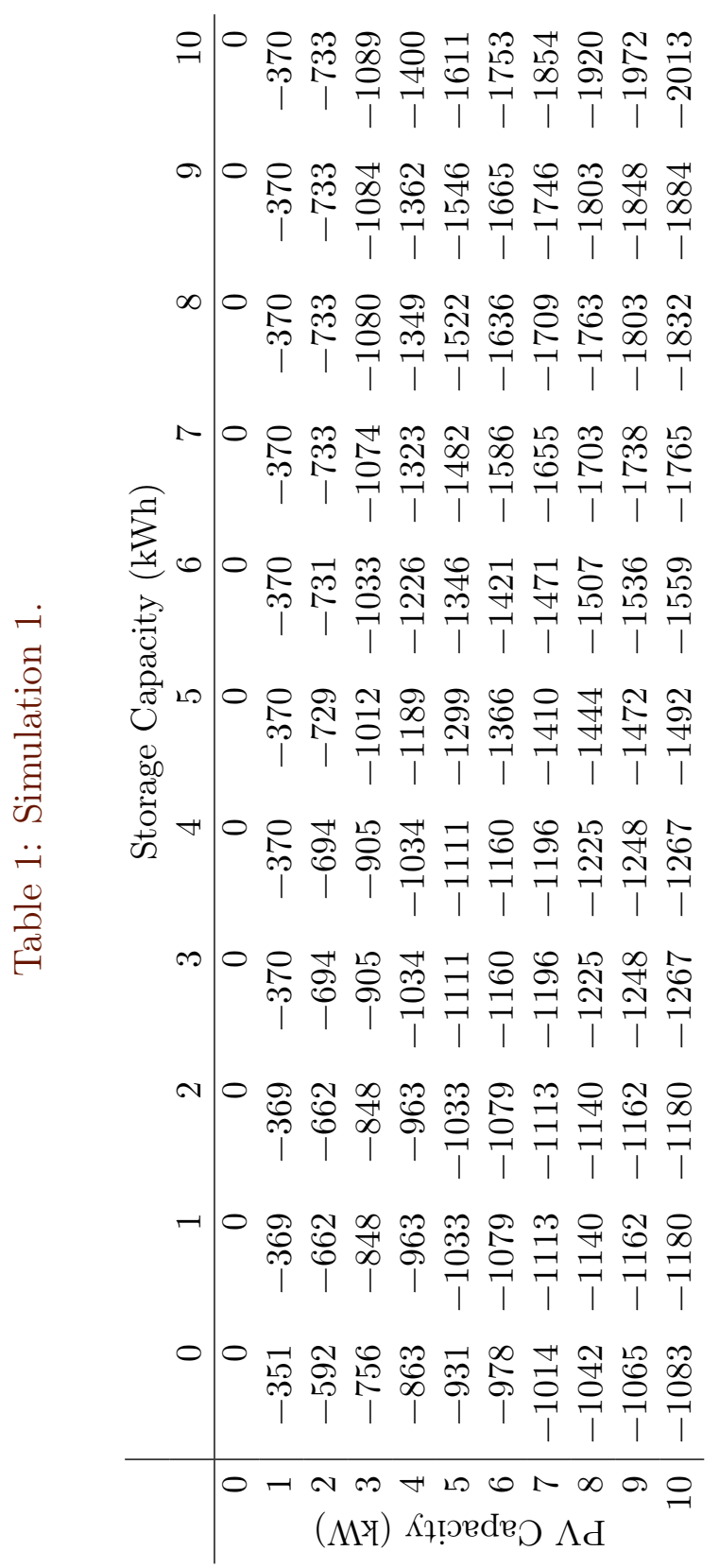




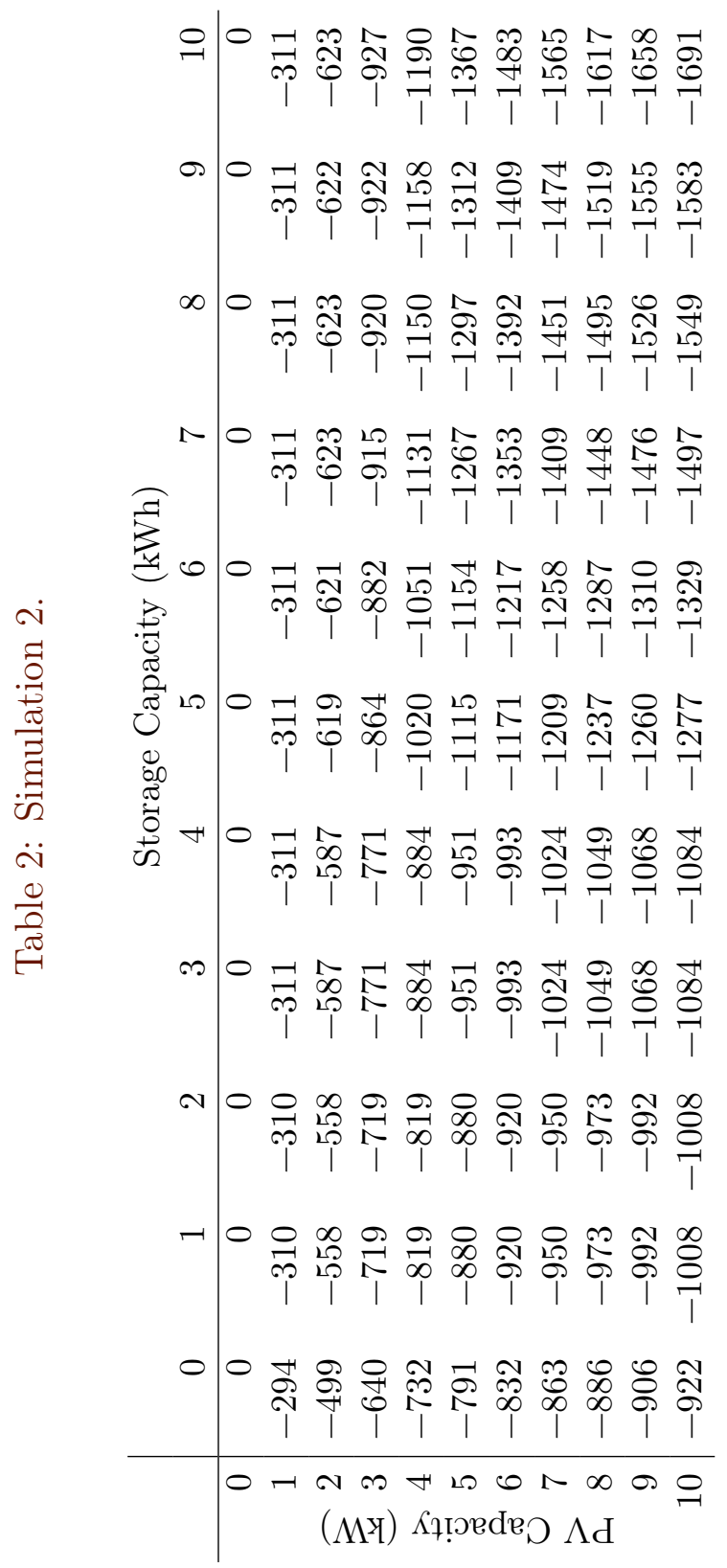




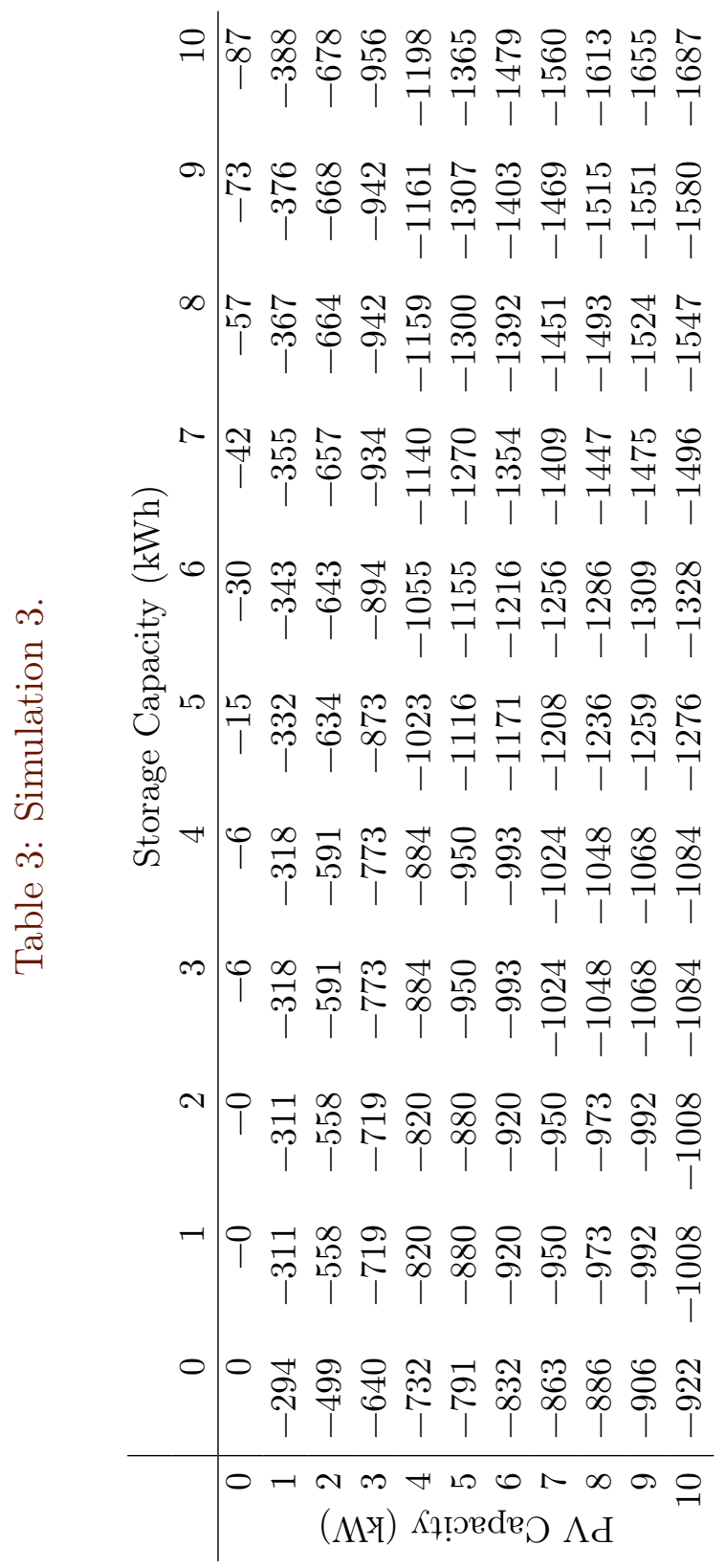




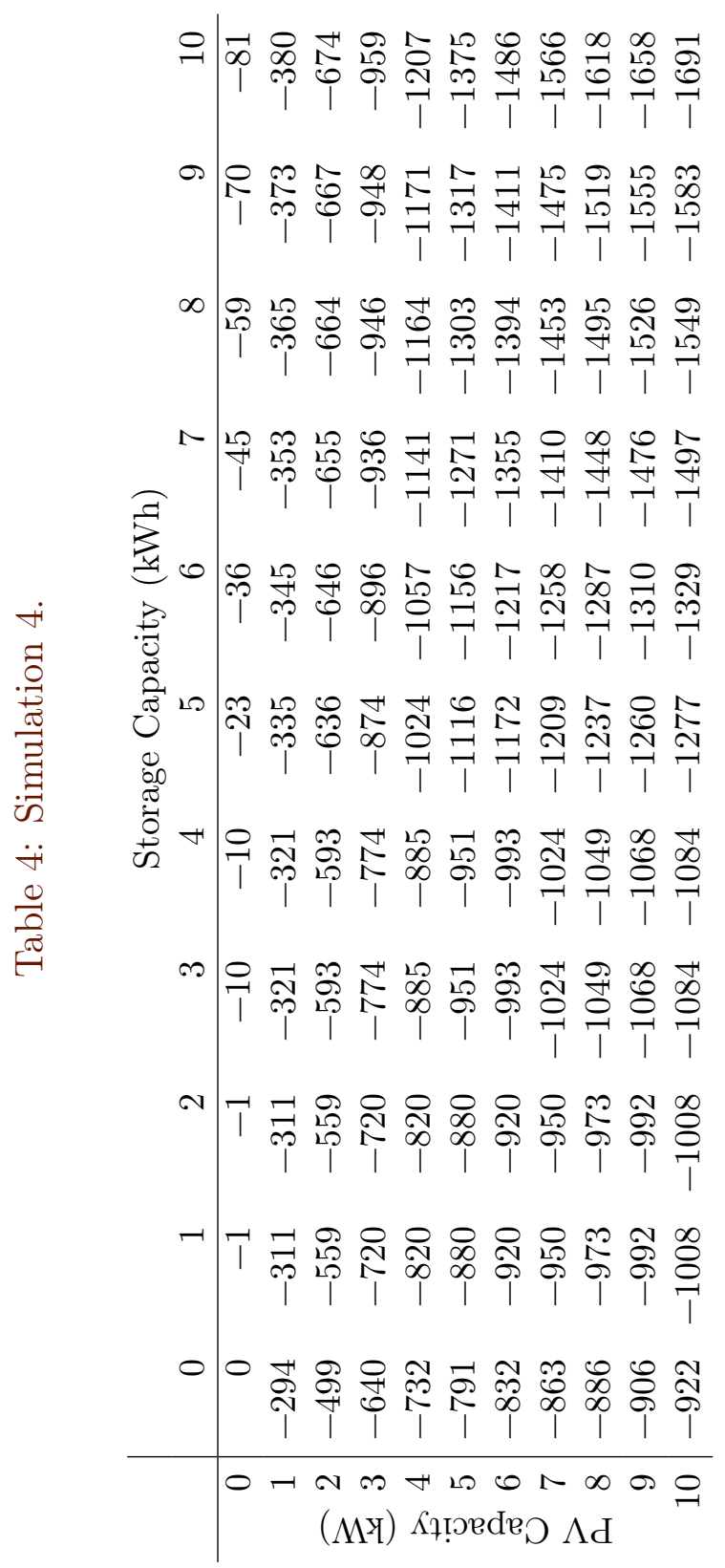


higher billing costs.

Simulation 3 differs from 4 in that simulation 4 has perfect knowledge of the electricity needs and the PV output at the shoulder and peak times. However, the difference in savings between the two types of calculations is not great. This result suggests that perfect knowledge of PV output and load may not be as cost effective as simply targeting a full level of store in simulation 3-in this particular example. However, within the calculations, less is imported from the grid in simulation 4 compared to simulation 3, meaning that the battery is used more efficiently.

\section{Conclusion}

This paper presented the work undertaken as part of MISG 2016, where estimating the value of various combinations of PV, storage and tariffs was investigated. A simulation-based solution was adopted to solve this problem, applied to one household, and presented here. It took into account different combinations of PV and storage sizing and looked at how much saving could be expected under different tariff structures. For this, detailed (half hourly) consumption data was required. Such data is now more widely available thanks to the installation of metered data in many premises. This approach showed that applying this algorithm could help the customer determine the size of the PV and the battery to be installed, as well as choose which tariff structure would best suit them.

To develop a product widely applicable to its customers rather than such an individually-based product, it is possible to create many semi-tailored products where clusters of consumers can be identified and to which a solution product would be offered. While this paper showed that there was a wide diversity of consumption between and within the users, general trends of groups of consumption can still identified. In that case, applying the simulation model presented here to different clusters is the way this can be implemented. 
Acknowledgments We thank Chris White and Ergon Energy for the chance to work on this problem at MISG. The following people worked on this project during MISG and we acknowledge them for their ideas and their participation: Kirrilee Rowe, Luigi Cirocco, Silvio Tarca, Minh Tran, Soorena Ezzati, Joon Heo, Manju Agrawal, Noel Thompson, Charles Ling, Kaye Marion.

\section{References}

[1] Clastres, C., T. T. Ha Pham, F. Wurtz and S. Bacha (2010). Ancillary services and optimal household energy management with photovoltaic production. Energy 35(1): 55-64. M6

[2] Eckhouse, B. (2016). Energy Storage Costs Expected to Slide $41 \%$ by 2020, GTM Says. https:

//www.bloomberg.com/authors/ASeC4C-3atc/brian-eckhouse M5

[3] Iwafune, Y., T. Ikegami, J. G. d. S. Fonseca, T. Oozeki and K. Ogimoto (2015). Cooperative home energy management using batteries for a photovoltaic system considering the diversity of households. Energy Conversion and Management 96: 322-329. M6

[4] Jones, R. V., A. Fuertes and K. J. Lomas (2015). The socio-economic, dwelling and appliance related factors affecting electricity consumption in domestic buildings. Renewable and Sustainable Energy Reviews 43: 901-917. M7

[5] Jovanovic, R., A. Bousselham and I. S. Bayram (2016). Residential Demand Response Scheduling with Consideration of Consumer Preferences. APPLIED SCIENCES-BASEL 6(1): 16. M7

[6] Kang, J. and J. H. Lee (2015). Electricity Customer Clustering Following Experts' Principle for Demand Response Applications. ENERGIES 8(10): 12242-12265. M7 
[7] McDonald B., Pudney P. and Rong J. (2014). Pattern recognition and segmentation of smart meter data. ANZIAM 54: 105-150. M7, M10

[8] Nykvist, B. and M. Nilsson (2015). Rapidly falling costs of battery packs for electric vehicles. Nature Climate Change 5(4): 329-332. M5

[9] Parkinson, G. (2014). Why EVs will make solar viable without subsidies. REneweconomy. M5

[10] Pudney, P., A. Grantham, L. A. Ward, D. Whaley and J. Boland (2016). The viability of electrical energy storage for Lochiel Park households. Cooperative Research Centre for Low Carbon Living, The University of $N S W$ and the University of South Australia: 1-29. M16

[11] The State of Queensland (2015). Queensland Government Gazette. Queensland Competition Authority. 369: 14. M9, M23

[12] Romm, J. (2016). The Battery Miracle Will Transform Both Transportation And Power Generation. Climate Progress. M5

[13] Yang, Y., W. Zhang, J. Jiang, M. Huang and L. Niu (2015). Optimal Scheduling of a Battery Energy Storage System with Electric Vehicles' Auxiliary for a Distribution Network with Renewable Energy Integration. Energies 8(10): 10718-10735. M6

\section{Author addresses}

1. John Boland, School of ITMS, University of South Australia, South Australia 5095, Australia

mailto: john.boland@unisa.edu.au orcid:0000-0003-1132-7589

2. Fanny Boulaire, Queensland University of Technology, Brisbane, Queensland Australia mailto:fanny. boulaire@qut.edu.au 
orcid:0000-0001-8941-4872

3. Adrian Grantham, School of ITMS, University of South Australia, South Australia 5095, Australia

mailto:adrian.grantham@mymail.unisa.edu .au orcid:0000-0001-5257-5349

4. Chris White, Ergon Energy

mailto: chris. white@ergon. com.au orcid:0000-0001-6562-930X 